\title{
Caracterização do solo em área submetida a derramamento de lixiviado decorrente de aterro sanitário
}

\author{
Characterization of soil in an area subject to spills resulting from landfill leachate \\ Pedro Daniel da Cunha Kemerich, Guilherme Barros, Willian Fernando de Borba, Ademir Eloi Gerhardt, Carlos Eduardo \\ Balestrin Flores, Eduardo Dalvani Schwaab, Bruna Cardozo, Fernando Ernesto Ucker \\ Laboratório de Planejamento e Monitoramento Ambiental - LPMA/UFSM, \\ Curso de Engenharia Ambiental da Universidade Federal de Santa Maria - UFSM/CESNORS
}

\section{Resumo}

O crescimento populacional e o consumismo criado nas civilizações contemporâneas fazem que o volume de resíduos gerados seja cada vez mais crescente, desta forma, surge a cada vez mais a necessidade de se dar um destino correto a esses materiais que são descartados. Os aterros sanitários fazem um contraponto à antiga forma de disposição dos resíduos sólidos, o lixão. Tendo como principais diferenças a impermeabilização do solo e a cobertura periódica das camadas de lixo com uma camada de terra. A lixiviação e a decomposição são processos naturais que conduzem a formação do chorume. Desta forma este estudo tem como objetivo, apresentar a caracterização do solo em área submetida a derramamento de chorume decorrente de aterro sanitário, localizado no município de Seberi-RS. As amostras de solo foram coletadas através de tradagem manual, em 11 (onze) pontos diferentes, sendo dois pontos brancos. Os resultados das análises de laboratório, mostram que, as concentrações de Potássio, apresentam uma média de 358,55 $\pm 147,87 \mathrm{mg} \mathrm{kg}^{-1}$, as concentrações de Cálcio apresentaram uma média de 1276,84 $\pm 398,8 \mathrm{mg} \mathrm{kg}^{-1}$, as porcentagens de argila apresentaram uma média de 47,55 $\pm 10,11 \%$, os valores de $\mathrm{pH}$ em H2O apresentaram uma média na área de 5,2 $\pm 0,29$, a área apresentou uma média de matéria orgânica de 3,43 $\pm 1,63 \%$, as concentrações de Alumínio apresentaram uma média de $6,54 \pm 4,20 \mathrm{mg} \mathrm{kg}^{-1}$. Alguns parâmetros quando comparados aos pontos considerados brancos apresentaram uma pequena alteração, porém pode-se considerar que a área exposta é pouco vulnerável a contaminação.

Palavras-chave: Contaminação, resíduos sólidos, chorume.

\begin{abstract}
Population growth and consumerism in contemporary civilizations created, make the volume of waste generated is ever increasing, there is increasingly a need to give a correct destination of those materials that are discarded. Landfills are a counterpoint to the old way of disposal of solid waste, the landfill. With the major differences in soil sealing and coverage of periodic layers of trash with a layer of earth. Leaching and decomposition are natural processes that lead to formation of leachate. Therefore, this study aims to present the characterization of the soil in an area under the resulting slurry spill landfill, located in the municipality of Seberi-RS. Soil samples were collected from berehole manual, in 11(eleven) different points, two white dots. The results of laboratory analyzes show that the concentrations of potassium, have an average of $358,55 \pm 147,87 \mathrm{mg} \mathrm{kg}^{-1}$, the concentrations of calcium showed an average of $1276,84 \pm 398,8 \mathrm{mg} \mathrm{kg}^{-1}$ the percentage of clay had an average of 47,55 $\pm 10,11 \%$, pH values in $\mathrm{H} 2 \mathrm{O}$ had an average area of 5,2 $\pm 0,29$, the area showed a mean of $3,43 \pm 1.63 \%$ Aluminum concentrations showed a mean of $6,54 \pm 4,20 \mathrm{mg} \mathrm{kg}^{-1}$. Some parameters when compared with white spots were considered a minor change, but it can be assumed that the exposed area is less vulnerable to contamination.
\end{abstract}

Keywords: Contamination, solid waste, slurry. 


\section{INTRODUÇ̃̃O}

A disposição e o gerenciamento de resíduos urbanos e industriais constituem um dos grandes desafios do gerenciamento ambiental no Brasil. Atualmente no Brasil são geradas diariamente 240 mil toneladas de resíduos. A maior parte desses ainda é disposta no solo, sem nenhum controle ou cuidado, provocando então sérias consequências para o ecossistema natural e para a saúde humana, principalmente nos grandes centros urbanos (GIORDANO et al., 2002).

Com a intensificação do processo industrial, aliada ao crescimento da população e à conseqüente demanda por bens de consumo, o homem tem produzido quantidades significativas de resíduos sólidos, que acabam sendo constituídos de uma mistura muito complexa e de natureza diversa, cujos principais constituintes são: material orgânico, papel, vidro, plástico e metais (LEITE et al.,2004).

A disposição de resíduos sem os devidos cuidados pode gerar a proliferação de agentes patogênicos, poluição do solo, do ar e de recursos hídricos através da migração dos elementos constituintes do chorume e de gases produzidos através do processo de degradação da matéria orgânica desses depósitos (TARTARI, 2005).

A lixiviação ocorre quando os constituintes químicos de um material sólido são extraídos ou solubilizados pela ação de um fluido percolante (normalmente, a água). A decomposição é o processo de transformaçao que ocorre em moleculas organicas onde elas são transformadas em compostos mais simples. Ambos são processos naturais que conduzem a formaçao de um liquido denso, de cor escura, odor desagradavel, conhecido popularmente como chorume (TAVARES, 2011).

O chorume é formado pela solubilização de componentes do lixo na água, principalmente da chuva. Essa água fica em contato com o lixo durante certo período e, por ação natural da gravidade, percola através da porosidade existente até encontrar uma camada impermeável do solo, formada por rochas, ou mesmo superfícies previamente preparadas para receber o lixo, onde acumula e escoa (TARTARI, 2003).

Esse líquido pode conter altas concentrações de metais pesados, sólidos suspensos e compostos orgânicos originados da degradação de substâncias que são metabolizadas, como carboidratos, proteínas e gorduras. Por apresentar substâncias altamente solúveis, pode escorrer e alcançar as coleções hídricas superficiais ou até mesmo infiltrar- se no solo e atingir as águas subterrâneas, comprometendo sua qualidade e potenciais usos (SISINO \& MOREIRA, 1996).

O estudo dos metais pesados no chorume e em outras matrizes ambientais vem sendo considerado prioritário nos programas de promoção da saúde em escala mundial (SEGURA-MUÑOZ, 2003).

Muitos metais são essenciais para o crescimento de todos os tipos de organismos, desde bactérias até o ser humano, mas eles são requeridos em baixas concentrações, porque, quando em altas concentrações, podem danificar os sistemas biológicos por apresentarem características bioacumulativas no organismo.

A disposição final dos resíduos sólidos varia de acordo com a região onde é coletado, em torno de $71 \%$ do lixo coletado é destinado a aterros sanitários ou controlados. A quantidade e o tipo de chorume produzido estão relacionados com variações climáticas, volume das chuvas ocorridas na região, temperatura, tempo de residência dos resíduos no aterro e composição do lixo (SILVA \&FERREIRA, 2005).

O impacto produzido pelo chorume sobre o meio ambiente está diretamente relacionado com sua fase de decomposição. O chorume de aterro novo, quando recebe boa quantidade de águas pluviais é caracterizado por $\mathrm{pH}$ ácido, alta Demanda Bioquímica de Oxigênio (DBO5), alto valor de Demanda Química de Oxigênio (DQO) e diversos compostos potencialmente tóxicos. Com o passar dos anos há uma redução significativa da biodegradabilidade devido à conversão, em gás metano e $\mathrm{CO} 2$, de parte dos componentes biodegradáveis (SERAFIM et al, 2003).

$\mathrm{O}$ volume de chorume produzido num aterro varia sazonalmente em função das condições climáticas da região e do sistema de drenagem local, sofrendo a influência da temperatura, do índice de precipitação pluviométrica, da evapotranspiração, da existência de material de cobertura para as células, da permeabilidade do material de cobertura utilizado, da cobertura vegetal da área do aterro e ainda de muitos outros fatores. A melhor forma de se determinar a vazão de chorume gerada em um aterro é através da medição direta. Outra forma para se estimar as vazões de aterros sanitários é através de uma correlação direta com a geração de chorume em aterros conhecidos, embora, para isso, tenha que se admitir uma série de simplificações (MONTEIRO, 2001).

A formação do chorume é um processo natural, mas se este não é tratado e exposto ao meio ambiente, torna-se extremamente poluente, 
sendo potencial contaminante de lençóis freáticos e corpos d'água, comprometendo a saúde d população. A presença dos diversos poluentes no chorume impõe a necessidade de tratamento adequado antes de seu lançamento no corpo receptor. A caracterização do chorume permite, além de avaliar o potencial poluidor dos mesmos, eleger e adotar as melhores soluções técnicas para prevenção e mitigação de eventuais problemas causados pela inadequada disposição de resíduos em aterros (CONAMA, 2009).

O presente trabalho tem como objetivo identificar as alterações químicas no solo decorrente de vazamento de chorume de lagoa de tratamento em aterro sanitário.

\section{MATERIAIS E MÉTODOS}

\section{I Caracterização da área de estudo}

O município de Seberi está situado no noroeste do estado do Rio Grande do Sul, Brasil na latitude $27^{\circ} 28^{\prime} 4^{\prime \prime}$ S e longitude $53^{\circ} 24^{\prime}$ 09" O, com altitude de 546 metros do nível do mar, abrangendo uma área de $301 \mathrm{Km}^{2}$ e com população de 10,897 habitantes, sendo o mesmo pertencente à bacia hidrográfica do Rio Uruguai com clima subtropical úmido (IBGE, 2009). O Consórcio Intermunicipal de Gestão De Resíduos Sólidos (CIGRES), localizado na BR $386 \mathrm{Km} \mathrm{43,}$ Linha Osvaldo Cruz, é um consórcio, entre 29 municípios, abrangendo uma área total 7,77 ha, com abrangência de 4.883,60 Km², com 162 mil habitantes, recebendo cerca de 52 toneladas de Resíduos sólidos urbanos por dia.

\subsection{Localização dos pontos de amostragem e coleta de amostras}

A tradagem para coleta das amostras foi realizada em função da topografia existente no terreno e do fluxo preferencial de água superficial, determinado com o auxílio do software Surfer 9.0 da Golden Software, utilizando-se o método de interpolação matemática Krigagem. Foram considerados 11 pontos de coleta denominados: P1, P2, P3, P4, P5, P6, P7, P8, P9, e B1 - B2 que são os pontos brancos.

A figura 1 apresenta a localização dos pontos de coleta (P1, P2, P3, P4, P5, P6, P7, P8 e P9) e dos pontos brancos (B1 e B2), sendo apresentado o sentido do relevo na área. O ponto $\mathrm{P} 9$ apresenta-se com a menor cota do terreno, sendo assim a

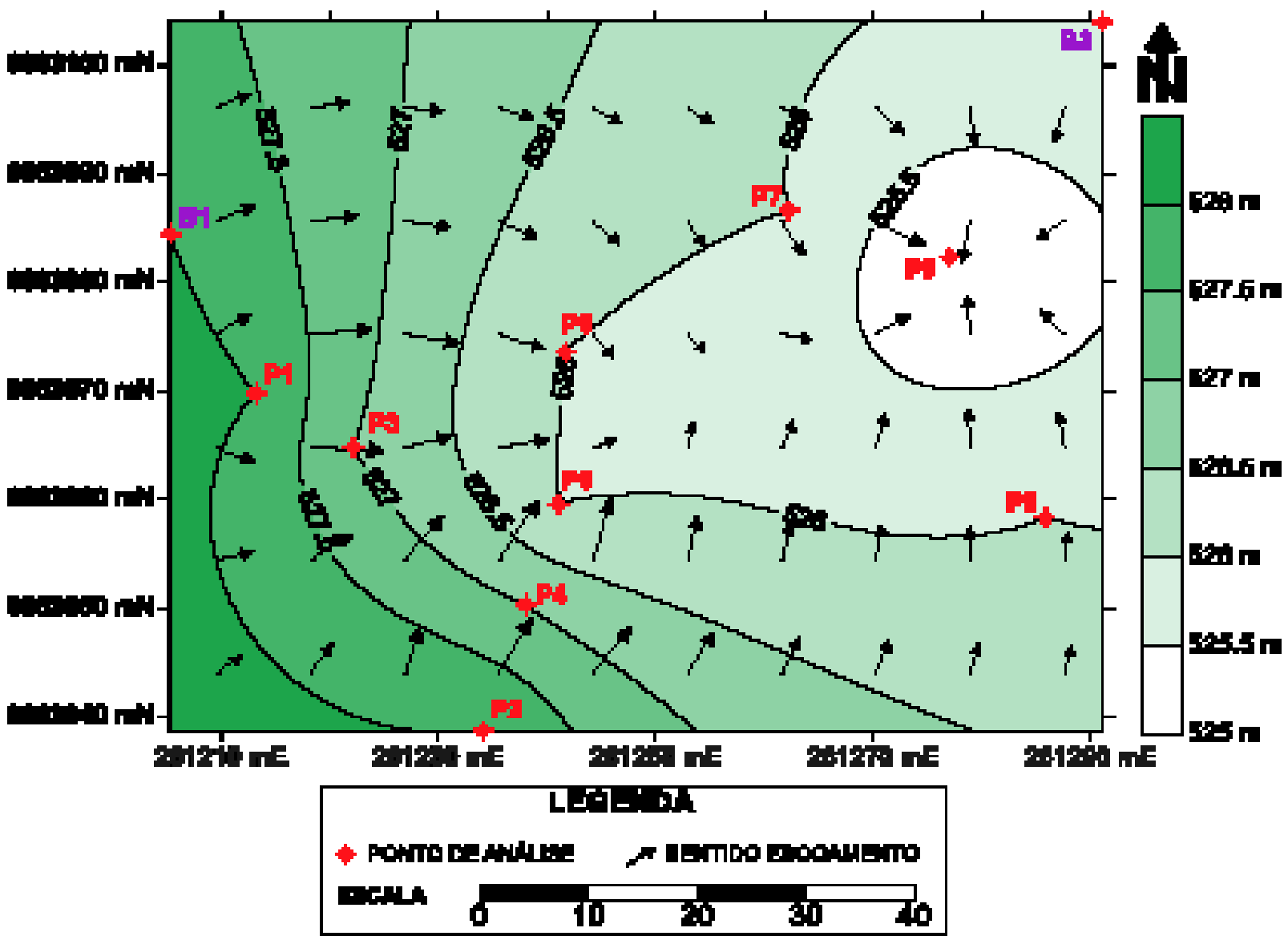

Figura 1. Cartograma da altitude e sentido do escoamento na área de estudo, Seberi-RS. 

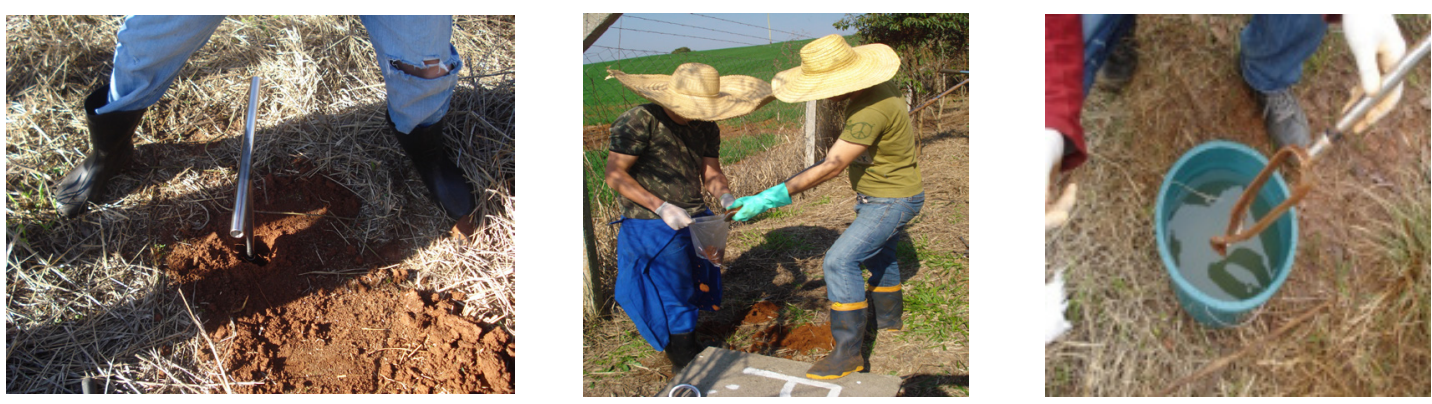

Figura 2. Tradagem efetuada utilizando trado manual Sonda terra $4 \mathrm{~m}$ (a), local de tradagem (b) e limpeza do trado em água destilada (c). Preparo de amostras e caracterização química do solo

tendência de escoamento na lavoura direciona-se ao mesmo. A maior parte dos pontos localiza-se a sudoeste da área, próximo ao local do derramamento (cotas maiores). Os pontos brancos estão a norte do local, área não atingida pelo chorume.

Para a coleta das amostras foi utilizado, um trado manual Sonda Terra de $3 \mathrm{~m}$ de comprimento (Figura 2a). Cada amostra coletada foi armazenada em sacos plásticos e recebeu identificação correspondendo à localização do ponto de amostragem e a profundidade da coleta. Nos 11 pontos analisados foram coletadas amostras a $20 \mathrm{~cm}$, totalizando 11 amostras (Figura 2b). Para evitar alterações nos resultados o trado era lavado com água destilada, conforme a Figura 2c.

$\mathrm{O}$ experimento foi conduzido em laboratório, a partir de amostras de solo coletadas na área afetada pelo chorume. A coleta das amostras sucedeu-se no mês do Agosto de 2011. Para realizar a análise das amostras, foram utilizados equipamentos laboratoriais e também algumas técnicas instrumentais, que permitiram a caracterização química do solo.

De cada amostra composta foram retiradas porções de aproximadamente 200 gramas, para avaliação das características químicas do solo. Dentre as características químicas, foram feitas as seguintes avaliações, utilizando-se protocolos descritos por Tedesco (1995): teor de fósforo, potássio, cálcio e magnésio no solo.

As determinações do conteúdo de alumínio no solo e da capacidade de troca de cátions (CTC) efetiva do solo foram realizadas de acordo com a metodologia descrita em EMBRAPA (1997). A análise da quantidade de matéria orgânica no solo foi feita de acordo com os protocolos descritos em EMBRAPA (1999).

A determinação do $\mathrm{pH}$ do solo foi feita mediante a utilização de um pHmêtro, sendo o aparelho da marca Tekna, modelo T-1000.

\subsection{Espacialização dos resultados}

Para a realização dos mapas foi utilizado o software SURFER 10 da Golden Software, como método de elaboração matemática foi utilizada a krigagem. Inicialmente foram lançados os valores para ponto de amostragem de solo (com o parâmetro a ser espacializado) com as coordenadas UTM (Universal Transverse Mercator) escolhendo-se a opção Countor Map e gerando-se um cartograma de contorno da superfície da área estudada, logo após foram espacializadas as informações de interesse com o uso da opção Post Map.

\section{RESULTADOS E DISCUSSÃO}

\section{I Concentração de Potássio $(K+)$}

A figura 3 apresenta as concentrações de Potássio nos 11 pontos analisados na lavoura exposta a chorume. Os pontos P7 e P9 apresentaram as menores concentrações de Potássio, e as maiores concentrações estão a sudoeste da área, sendo ponto $\mathrm{P} 1$ maior concentração.

As concentrações variaram de 100,00 a $616,00 \mathrm{mg} \mathrm{kg}^{-1}$ de Potássio, com uma média de $358,55 \pm 147,87 \mathrm{mg} \mathrm{kg}^{-1}$. Já Santana \& Encinas (2009), em análises de solo de uma área adjacente a aterro sanitário em Brasília, encontraram um valor médio de $92 \mathrm{mg} \mathrm{kg}^{-1}$, e os mesmos autores em solo de área adjacente a aterro sanitário em Goiânia, encontraram um valor médio de 83,5 $\mathrm{mg} \mathrm{kg}{ }^{-1}$.

A figura 4 apresenta as concentrações de Cálcio nos 11 pontos analisados na lavoura de Soja exposto a chorume. As maiores concentrações de Ca estão a norte da área, sendo os valores dos pontos brancos maiores do que os pontos expostos a chorume. Menores concentrações são observadas nos pontos P3, P4 e P5.

As concentrações de Cálcio apresentaram 


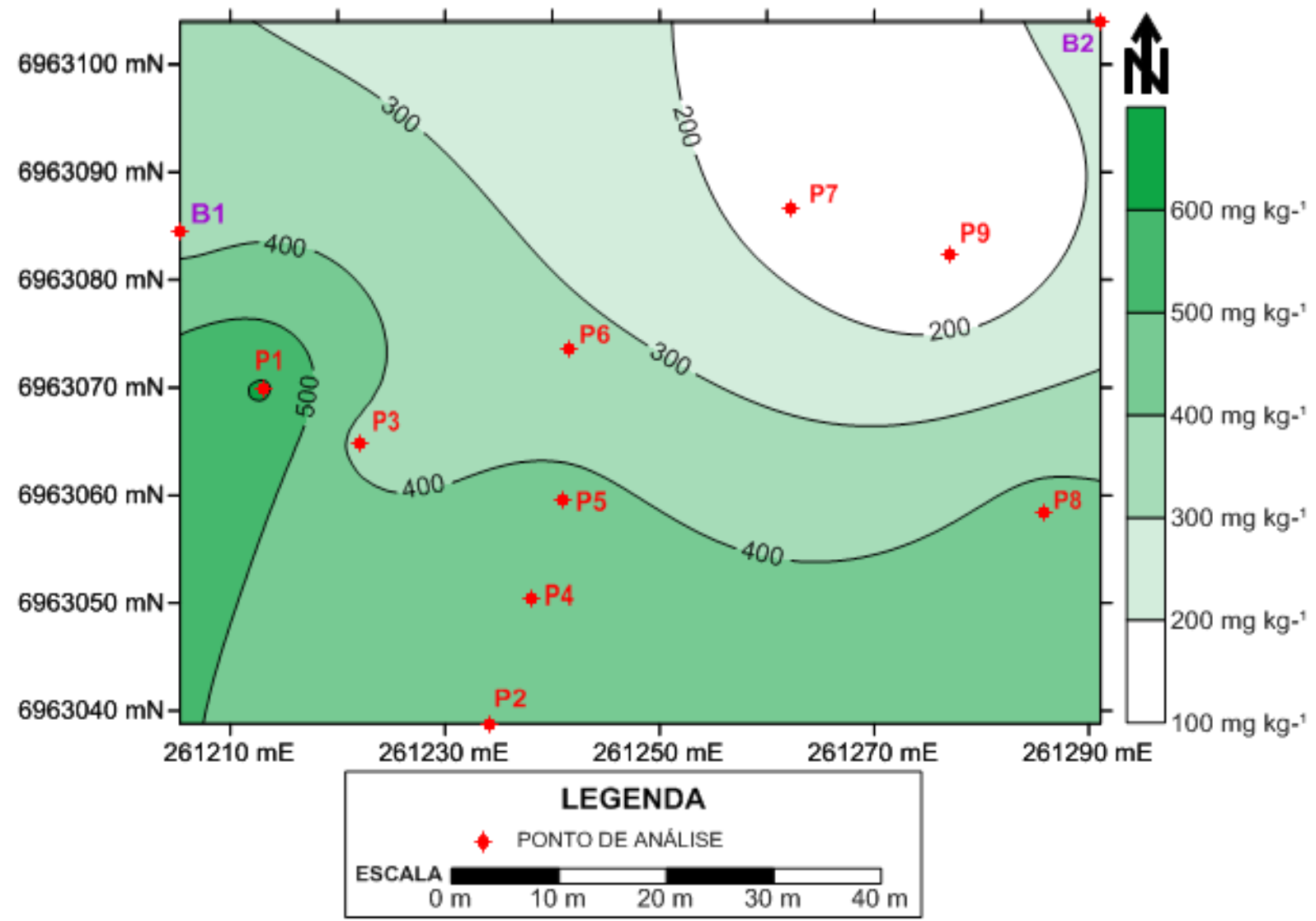

Figura 3. Cartograma da concentração de Potássio na área de estudo, Seberi-RS. Concentração de Cálcio (Ca+2)

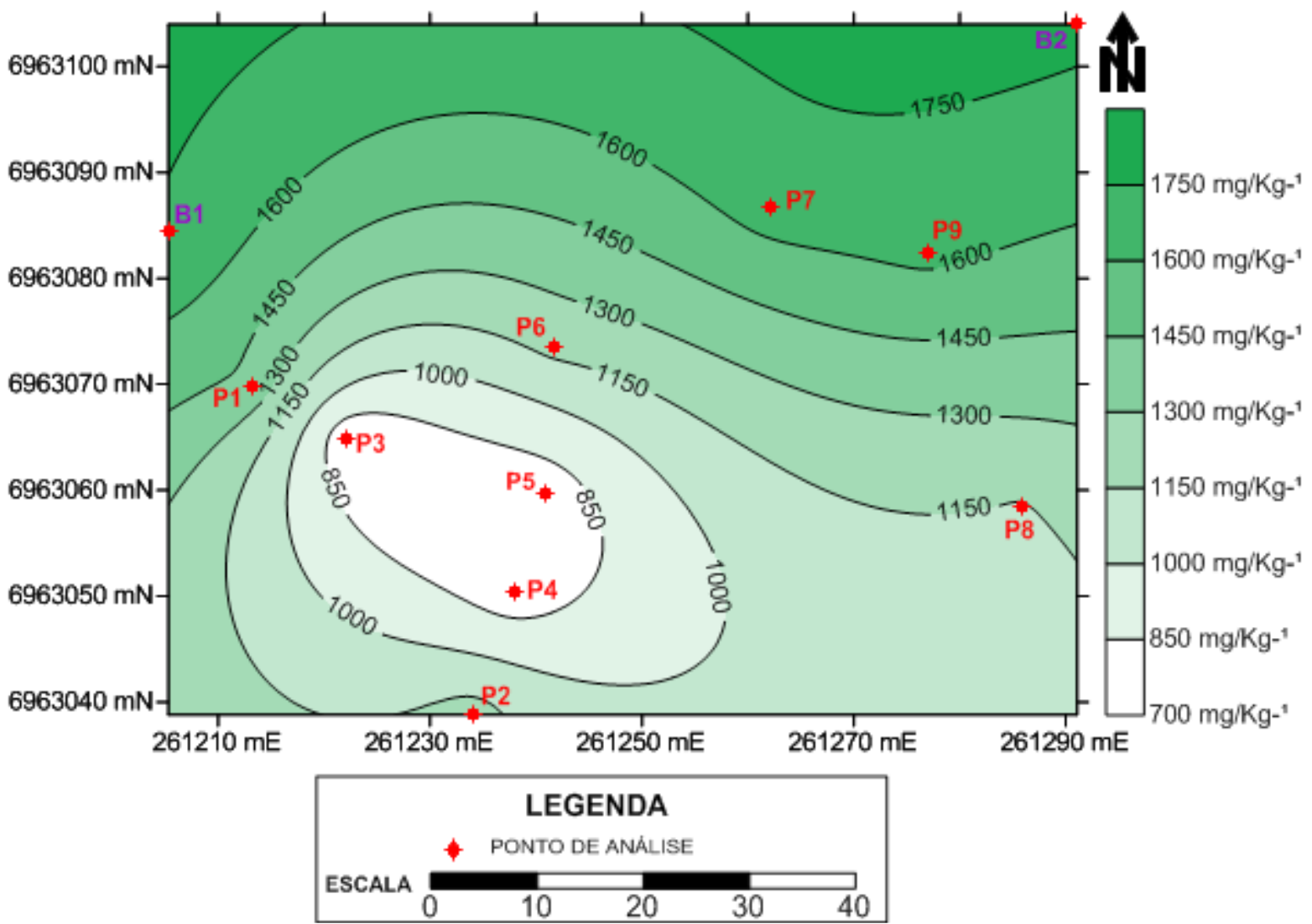

Figura 4. Cartograma da concentração de Cálcio na área de estudo, Seberi-RS. 
uma média de $1276,84 \pm 398,8 \mathrm{mg} \mathrm{kg}^{-1}$, apresentando assim uma variação grande entre os pontos, atingindo máximo de $1780,55 \mathrm{mg} \mathrm{kg}^{-1}$ no ponto B2 e mínimo de $748,49 \mathrm{mg} \mathrm{kg}^{-1}$ no ponto $\mathrm{P} 3$.

Konrad e Castilho (2001) trabalhando em um Planossolo Eutrófico na cidade de Pelotas - RS, obtiveram concentrações de $0,001 \mathrm{mg} \mathrm{kg}^{-1}$ de Cálcio, enquanto que Carvalho et al. (2011) encontraram concentração de $0,26 \mathrm{mg} \mathrm{kg}^{-1} \mathrm{em}$ um Argissolo Bruno Acizentado, na camada de 0 a $20 \mathrm{~cm}$, sob uso de frutíferas, também em Pelotas - RS.

\subsection{Argila}

A figura 5 apresenta a porcentagem de argila nos 11 pontos analisados na lavoura de Soja exposto a chorume. As maiores porcentagens de argila esta a nordeste da área, com o maior valor no ponto P7. Menores concentrações são observadas nos pontos P1 e no ponto branco 1 (B1).

Streck et al. (2008) afirma que os Latossolos do Rio Grande do Sul apresentam cerca de $42 \%$ de argila. A argila é importante em áreas de disposição de resíduos, pois ajuda reduzindo a vulnerabilidade de contaminação do aquífero.
Segundo FEPAM (2001) solos com teores maiores de $35 \%$ de argila, apresentam uma alta resistência a impactos ambientais, assim apenas o ponto Branco 1, apresentou teor de argila menor que $35 \%$.

As porcentagens de argila apresentaram uma média de 47,55 $\pm 10,11 \%$, levando em consideração a pequena área, ocorreu uma grande variação no percentual de argila da área, atingindo máximo de $59 \%$ no ponto P7 e mínimo de $22 \%$ no ponto B1.

\subsection{Potencial de Hidrogênio lônico em Água ( $\mathrm{pH}$ $\mathrm{H} 2 \mathrm{O}$ )}

A figura 6 apresenta o $\mathrm{pH}$ em água dos 11 pontos analisados na área exposta a chorume. Os maiores valores de $\mathrm{pH}$ estão a leste da área e no ponto P1. Menores valores são observados no ponto B3 e no ponto branco 1 (B1).

Valores semelhantes foram encontrados para Latossolo Vermelho em Passo Fundo - RS, por Spera et al. (2008) no qual o valor foi de 4,9 sob uso de campo nativo, Oliveiro (2008) na cidade de Cruz Alta - RS, encontrou de 4,5.

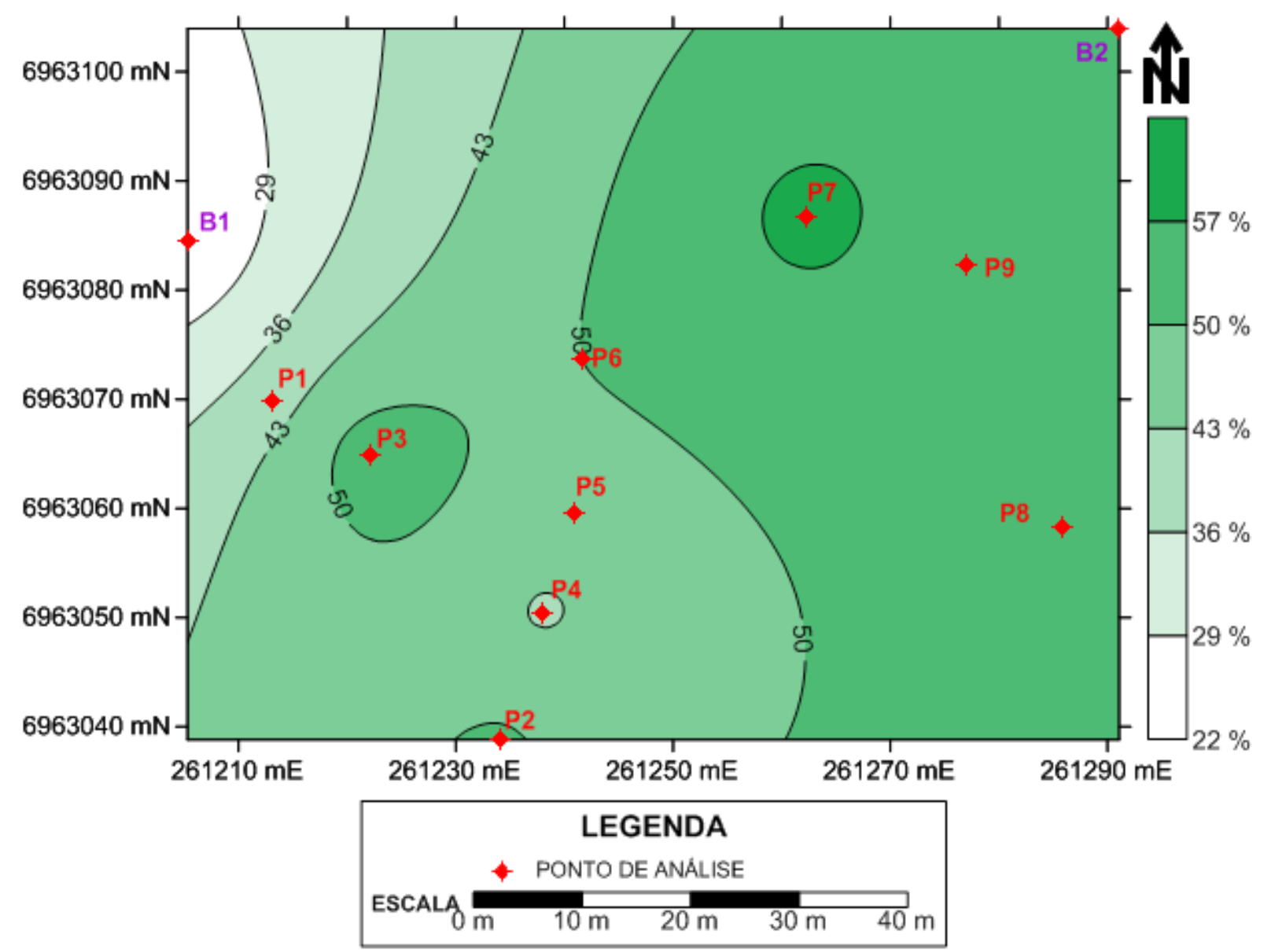

Figura 5. Porcentagem de argila na área de estudo, Seberi-RS. 


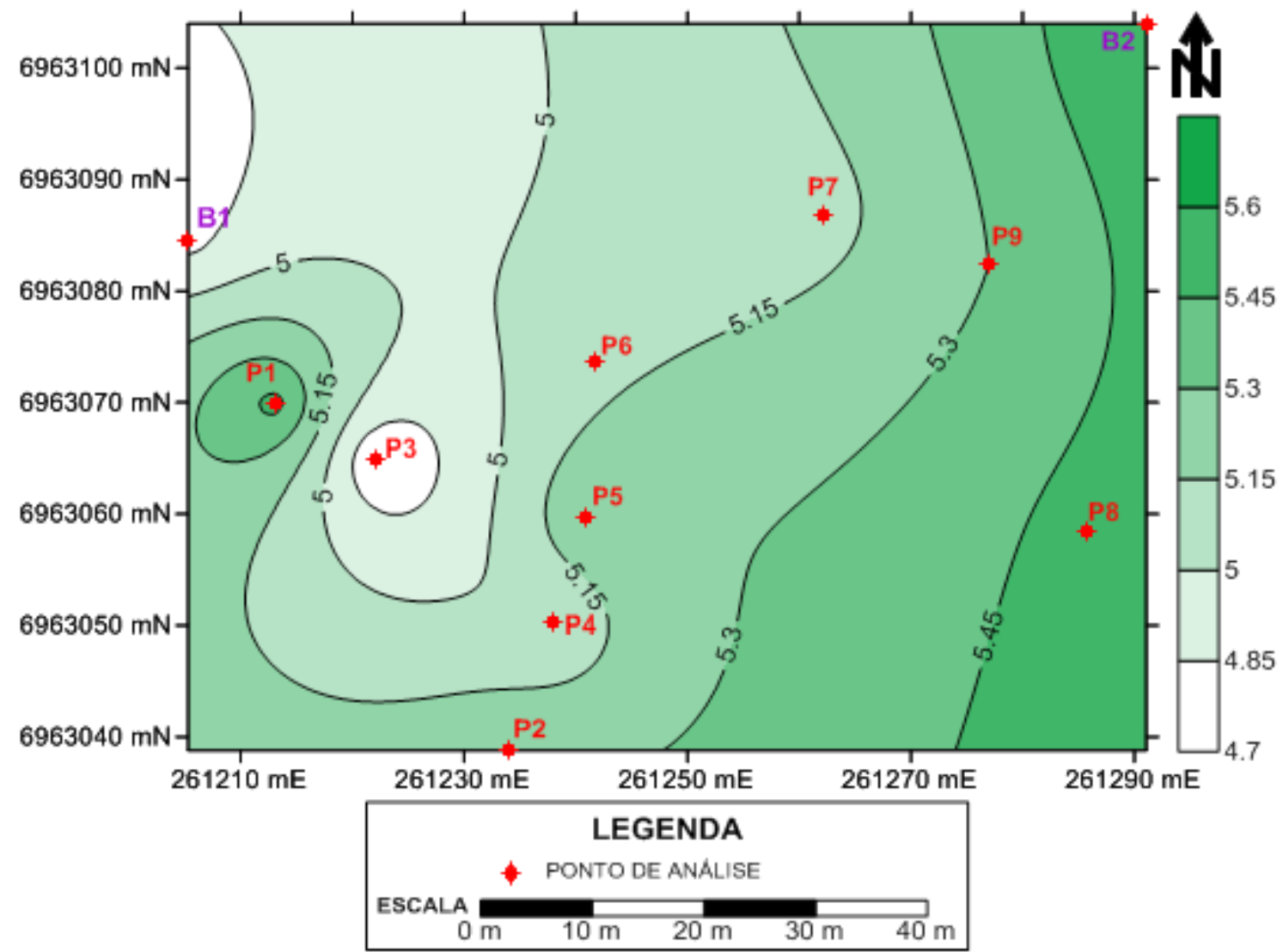

Figura 6. Valores de pH em água nos pontos analisados, Seberi-RS.

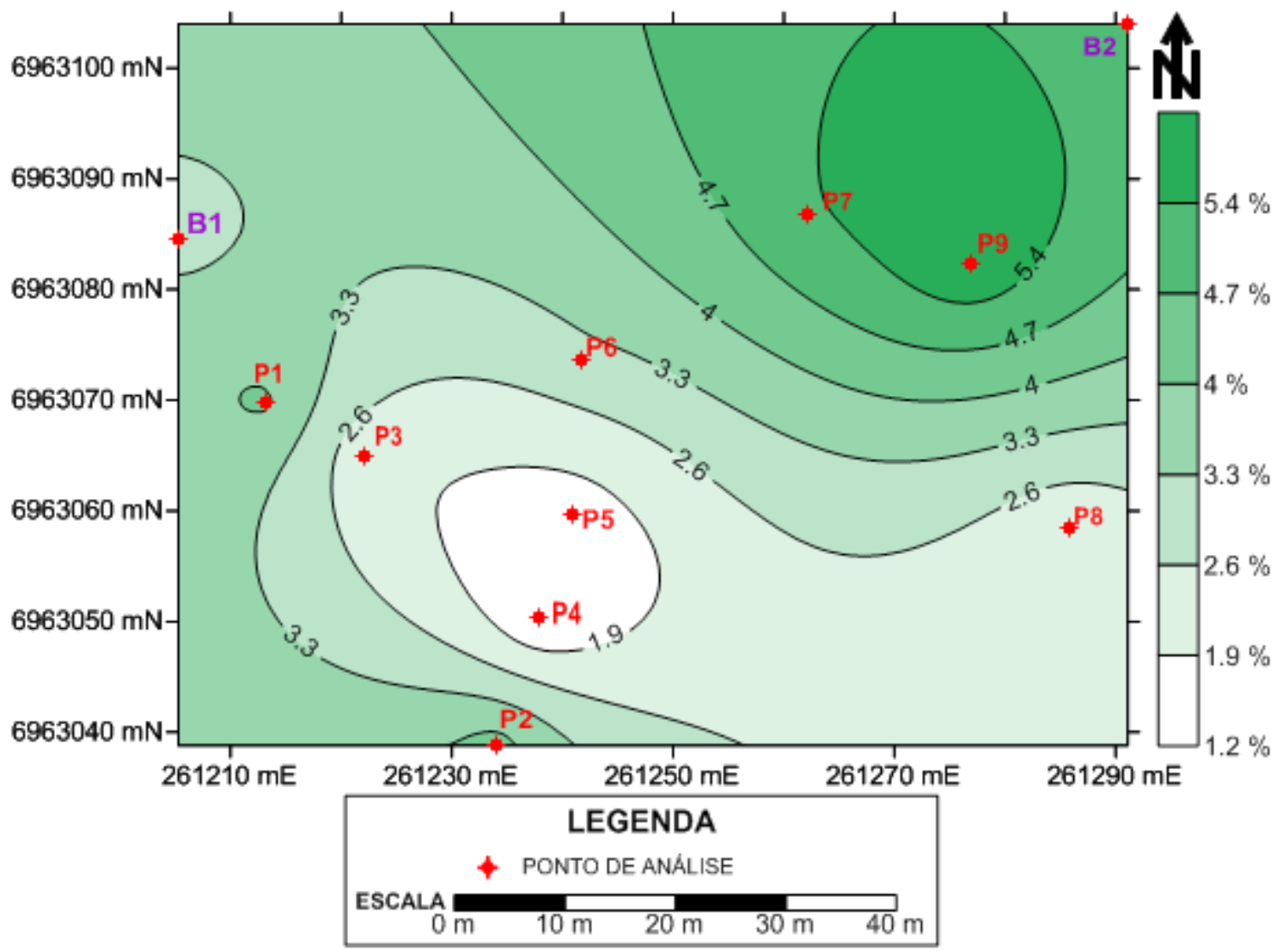

Figura 7. Porcentagem de Matéria Orgânica no solo, Seberi-RS. 
Os valores de $\mathrm{pH}$ em $\mathrm{H} 2 \mathrm{O}$ variaram de 4,7 no ponto $\mathrm{P} 3$ a 5,6 no ponto B2, tendo uma média na área de 5,2 $\pm 0,29$.

\subsection{Matéria orgânica (M.O.)}

A figura 7 apresenta a porcentagem de M.O. presente nas amostras, nos 11 pontos na lavoura exposta a chorume. Os pontos P7 e P9 apresentaram as maiores porcentagens de matéria orgânica, e ao contrario dos mesmo nos pontos P4 e P5 apresentou-se os menores valores.

A área apresentou uma média de matéria

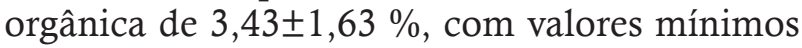
de $1,2 \%$ no ponto $\mathrm{P} 4$ e valor máximo no ponto P9 $(6,00 \%)$.

Na cidade de Passo Fundo - RS, Spera et al. (2008) encontraram valores na ordem de 31,0 g dm - 3 em um Latossolo Vermelho sob uso de campo nativo. Oliveiro (2008) na cidade de Cruz Alta - RS, encontrou 32 mg kg de matéria orgânica.

\subsection{Alumínio (Al+3)}

A figura 8 apresenta as concentrações de Alumínio nos 11 pontos analisados na lavoura exposta a chorume, na maioria dos pontos apresentaram-se valores semelhantes, tendo maiores variações nos pontos $\mathrm{P} 1, \mathrm{P} 8$ e B2.

As concentrações de Alumínio apresentaram uma média de $6,54 \pm 4,20 \mathrm{mg} \mathrm{kg}^{-1}$, atingindo máximo de $8,99 \mathrm{mg} \mathrm{kg}^{-1}$ na maioria dos pontos (P2, P3, P4, P5, P6, P7, P9 e B1), enquanto isso nos restantes não foi possível à identificação da concentração por apresentar-se abaixo do limite de detecção. Valores estes que podem ser considerados baixos, em se comparando com resultados obtidos por Venezuela (2001), onde após tratamentos com compostos de lixo as análises de solo apresentaram um valor médio de $55000 \mathrm{mg} \mathrm{kg}^{-1}$,e que mesmo assim, após análise de metais tóxicos no solo adubado com doses crescentes de composto de lixo e de posse dos resultados destes mesmos metais nas partes comestíveis das culturas, pode-

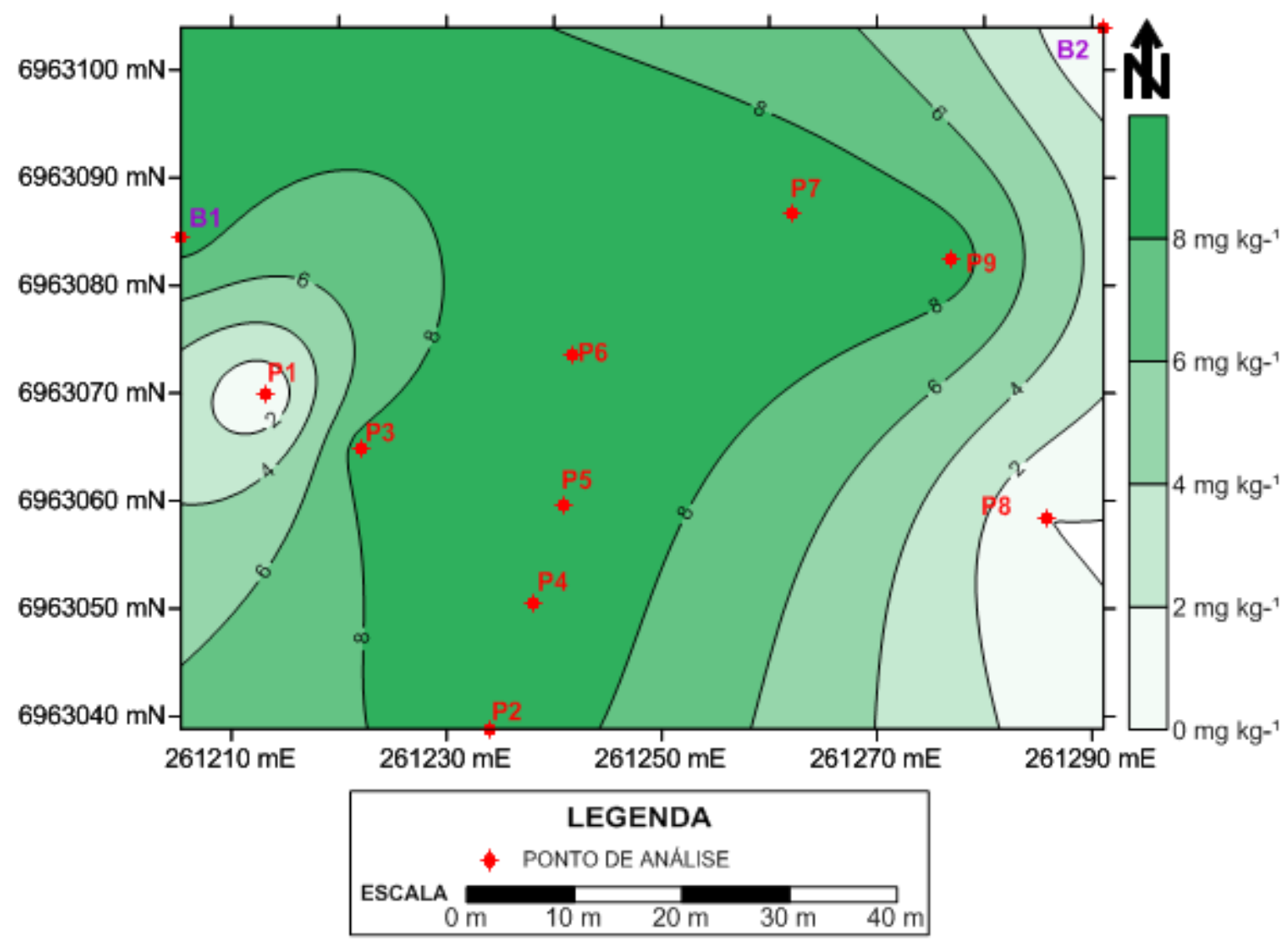

Figura 8. Concentrações de Alumínio na área de estudo, Seberi-RS 
-se afirmar que para este tipo de experimento o uso deste composto de lixo como nutriente para o solo não oferece risco de intoxicação já que a concentração de metais tóxicos nos alimentos encontra-se de acordo com os limites encontrados em plantas.

Com base na figura 8 , a área em estudo teve em relação ao B1 não obteve variação, podendo-se afirmar que não sofreu interferência.

\section{CONCLUSÃO}

Alguns parâmetros quando comparados aos pontos considerados brancos apresentaram uma pequena alteração, porém pode-se considerar que a área exposta é pouco vulnerável a contaminação.

Percebe-se que em alguns casos os maiores valores encontrados para os parâmetros encontram-se nos pontos brancos, o que demonstra que o material transportado até a lavoura não alterou quimicamente o meio onde foi depositado. Dessa maneira pode-se afirmar que boa parte do material transportado era o solo presente nas paredes da lagoa do sistema de tratamento.

\section{REFERÊNCIAS}

CARVALHO, J. dos. S.; ABEIJONS, L. M.; SANTOS, L. C. de; SILVEIRA, C. A. P.; PILLON, C.A. Alterações na biomassa microbiana de um argissolo sob cultivo de pessegueiro e doses de agromineral fonte de potássio. In: XX Congresso de Iniciação Científica da Universidade Federal de Pelotas, Pelotas, Brasil, 2011.

CONAMA. Conselho Nacional do Meio Ambiente. Dispõe sobre os critérios e valores orientadores de qualidade do solo quanto à presença de substâncias químicas e estabelece diretrizes para o gerenciamento ambiental de área contaminada por essas substâncias em decorrência de atividades antrópicas. In: Resolução No 420 de 28 de Dezembro de 2009. Brasília, 2009. Disponível em: <http://homologa. ambiente.sp.gov.br/aquiferos/CONAMA\%20Resolucao\%202009_420.pdf>. Acesso em: 15 fev. 2011.

EMPRESA BRASILEIRA DE PESQUISA AGROPECUÁRIA - EMBRAPA. Sistema brasileiro de classificação de solos. Brasília: EMBRAPA, 1999.

EMPRESA BRASILEIRA DE PESQUISA AGROPECUÁRIA - EMBRAPA. Manual de métodos de análises de solo. Rio de Janeiro: EMBRAPA, 1997.

FEPAM. Fundação Estadual de Proteção Ambiental Henrique Luis Roessler. Mapa de Classificação dos Solos do Estado do Rio Grande do Sul quanto à Resistência a Impactos Ambientais. Porto Alegre: 2001.

GIORDANO, G.; FERREIRA, J. A.; RITTER, E.; CAMPOS, J. C.; ROSSO, T. C. A.; PIRES, J. C. A. Tratamento do Chorume do Aterro Metropolitano de Gramacho- Rio de Janeiro-BR. In: XXVIII Congreso Interamericano de Ingeniária Sanitaria y Ambiental, 2002, Cancun. Anales del XXVIII Congreso Interamericano de Ingeniaria Sanitaria y Ambiental. Cancun: AIDIS, 2002. v. 1.

IBGE. Município de Seberi, RS, Senso 2010. Disponível em: <http://www.ibge.gov.br/ cidadesat/ topwindow.htm?1>, acessado em: 23-02-2012.

KONRAD, E. E.; CASTILHOS, D. D. Atividade Microbiana Em Um Planossolo Após Adição de Resíduos de Curtume. Revista Brasileira de Agrociência. p.131-135, 2001.

LEITE, C. M. B.; BERNARDES, R. S. O.; SEBASTIÃO, A. Método Walkley-Black na determinação da matéria orgânica em solos contaminados por chorume. Revista Brasileira de Engenharia Agrícola e Ambiental, 2004; 8: 111-5.

MONTEIRO, J. H. R. P et al. Manual de gerenciamento integrado de resíduos sólidos. Rio de Janeiro: IBAM, 200 p., 2001.

OLIVEIRA, L. F. C. Emissões de CO2 do solo sob preparo convencional e palntio direto em latossolo vermelho do Rio Grande do Sul. Tese (Mestrado) Universidade Federal de Santa Maria ,80 pg, 2008.

SANTANA, O.A.; ENCINAS,J.I. Composição Química do Solo e da Água Subterrânea em Áreas Adjacentes a Aterros Sanitários. Revista Brasileira de Ciências Agrárias, Vol.4, Num.3, Julho-Setembro, 2009, p. 318-328, Universidade Federal Rural de Pernambuco.

SEGURA-MUÑOZ, S. I.; TAKAYANAGUI, A. M. M.; TREVILATO, T. M. B.; HERING, S. E. Metais pesados em líquido percolado e água subterrânea da área do aterro sanitário e incinerador de resíduos sólidos de Ribeirão Preto, São Paulo, Brasil. In: Anais de Trabalhos Completos do I Fórum das Uni- 
versidades Públicas Paulistas Ciência e Tecnologia em Resíduos. v. 1. São Paulo: Legis Summa; 2003; p. 937-48.

SERAFIM, A.C.; GUSSAKOV, K.C.; SILVA, F.; CONEGLIAN, C. M. R.; BRITO, N. N.; SOBRINHO, G.D. Chorume, impactos ambientais e possibilidades de tratamentos. Fórum de estudos contábeis, 3. São Paulo: UNICAMP, 2003.

SILVA, R. P.; FERREIRA, O. M. Aterro sanitário de Aparecida de Goiânia, Medição da vazão de chorume, Goiânia, 2005.

SPERA, S. T. Dispersão de argila em microagregados de solo incubado com calcário. Revista Brasileira de Ciências do Solo, 32:2613-2620, 2008, Número Especial.

SISINO, C.; MOREIRA, J. Avaliação da contaminação e poluição ambiental na área de influência do aterro controlado do Morro do Céu, Niterói, Brasil. Caderno Saúde Pública 1996; p. 12-23.

STRECK, E. V.; KÄMPF, N.; DALMOLIN, R. S. D.; KLAMT, E.; NASCIMENTO, P. C. do.; SCHNEIDER, P.; GIASSON, E.; PINTO, L. F. S. Solos do Rio Grande do Sul. Porto Alegre: EMATER/RS-ASCAR, 2008.

TARTARI, L. C. Avaliação do Processo de Tratamento do Chorume de Aterro Sanitário de Novo Hamburgo. Revista Liberato (Novo Hamburgo), Novo Hamburgo RS, v. 6, n. 6, p. 66-74, 2005.

TAVARES, B. F. D. Tratamento de chorume: Análise dos efluentes da evaporação forçada. Universidade Federal do Rio de Janeiro, Rio de Janeiro $\square$ RJ, 2011.

TEDESCO, M. J. Análise de solo, plantas e outros minerais. Porto Alegre: UFRGS, 1995.

VENEZUELA, T. C. Determinação de contaminantes metálicos (metal tóxico) num solo adubado com composto de lixo em área olerícola no município de Nova Friburgo, 2001, p.79. Tese, Toxicologia ambiental. Fundação Oswaldo Cruz. Escola Nacional de Saúde Pública. 